\title{
Community-Centers in Israel during the COVID-19 Pandemic-A Collective Impact
}

\author{
Esther Isler \\ The Faculty of Economics, West University of Timisoara, Timisoara, Romania \\ Email: etisler@matnasim.org.il
}

How to cite this paper: Isler, E. (2021). Community-Centers in Israel during the COVID-19 Pandemic-A Collective Impact. Advances in Applied Sociology, 11, 430-443. https://doi.org/10.4236/aasoci.2021.119038

Received: August 2, 2021

Accepted: September 13, 2021

Published: September 16, 2021

Copyright $\odot 2021$ by author(s) and Scientific Research Publishing Inc. This work is licensed under the Creative Commons Attribution International License (CC BY 4.0).

http://creativecommons.org/licenses/by/4.0/

\begin{abstract}
The COVID-19 epidemic is a natural disaster crisis on a global scale. Despite the extensive experience in emergency operations that the Israeli community-centers have accumulated during times of war, community centers were required to develop original methods in order to make their services accessible to the communities, especially in these times of social distance and quarantines. This study examined the implementation of three collaboration models that enabled joint action whether multi or single sector, using the unique assets of each sector or organization. Three models of collaborations aimed at producing a common social impact were examined: 1) The wisdom of the crowd; 2) Strategic cross-sectoral partnerships; and 3) Collective impact. Qualitative data was collected from community centers in five local authorities, in an attempt to determine which model was the most influential in the community centers' performance throughout the crisis. Interviews were conducted with ten senior managers in the community, as the performance of community centers throughout the pandemic was highly dynamic and could best be captured using this method. Results showed that the model of Collective Impact provided the most desired outcomes among the investigated models. Another important finding highlights the importance of the managers' experience in the community centers' performance. Based on these findings, conclusions and recommendations for future operations of third-sector organizations were drawn.
\end{abstract}

\section{Keywords}

Community Centers, Wisdom of the Crowd, Strategic Cross-Sectoral Partnerships, COVID-19 Pandemic, A Collective Impact

\section{Introduction}

This paper was written as COVID-19 in Israel was in remission, and a sense of 
routine returned to the lives of the Israeli population. During the height of the pandemic, many activities were performed by third sector organizations. The focus of this study is the community centers in Israel, which have always been at the forefront, supporting the population during routine and emergency periods.

The COVID-19 pandemic has had unique characteristics, to which governments as well as civil society organizations were not prepared. Still, Civil Society Organizations (CSOs) in Israel acted, during the crisis, as a leading resource for helping citizens, especially the elderly and weaker populations. When recreation venues, schools, and businesses were closed, and social distancing was implemented, volunteers in CSOs kept coming (Schmid, 2021). This study focuses on community centers and examines their performance during the outbreak of the COVID-19 Pandemic, and the model of management that they chose.

COVID-19 first broke out in Wuhan city, China in late 2019. In January 2020, the World Health Organization (WHO, 2020) announced that COVID-19 is a pandemic with a high risk of international spread. On March 13, 2020, the WHO announced that Europe has become the center of gravity of the pandemic. Until the end of March 2020, the USA was the country with the largest number of positively diagnosed people. The USA was followed by Brazil, India and other third world countries.

In most countries where the virus had spread, a policy of closure and isolation was used. On January 23, 2020, after it was discovered that the virus had spread outside China, the (Israel Ministry of Health, 2020a) issued guidelines on how to treat people developing the symptoms of the disease. On January 30, returnees from China were required to remain in quarantine for fear of contracting the virus, and flights from China to Israel were banned. On February 17, quarantine orders were extended to returnees from Singapore, Thailand, Macau (China), Hong Kong (China), and South Korea (Israel Ministry of Health, 2020b).

On February 18, the Israeli prime minister stated that the State of Israel had succeeded in preventing the virus from entering its territory. About ten days later, on February 27, 2020, the first coronavirus patient who was not in quarantine was discovered in Israel (Elkayam et al., 2020). The patient had returned from Italy four days earlier, leading to the first cases of infection in Israel. As a result of these and other cases, more than 5,000 Israelis were quarantined by the end of February 2020 (Israel Ministry of Health, 2020b).

According to the (Israel Ministry of Health, 2021), at the end of March in 2020 , the number of confirmed coronavirus patients in Israel was 4,347 of these 80 were in serious condition, 81 in moderate condition and 16 died. There were also 134 recoveries reported. In the following months, the virus continued to spread in Israel and a series of restrictions and precautions were taken as preventative measures. The restrictions included extensive closure, social distancing, and the obligation to wear masks.

The first positive turnaround in Israel occurred in the middle of April 2020, when for the first time since the outbreak of the virus, the number of daily con- 
firmed recoveries was higher than the number of daily confirmed cases (209 recovering compared to 158). From this date onwards, the restrictions on gathering, commerce and activity outside the home came into effect. These restrictions were almost completely released at the peak of the COVID-19 spread in Israel.

On December 20,2020, a national vaccination campaign was launched after the State of Israel began receiving millions of doses of vaccines it had purchased from Pfizer (Cohen, 2021). The rate of morbidity from the disease had decreased dramatically. On March 25, 2021, Health Minister Yuli Edelstein announced that more than half of the population completed two doses of vaccinations (Marziano, 2021). Following the success of the vaccination campaign, Israel gradually exited the closures and life almost completely returned to normal, including the opening of cafes and restaurants, cultural and sporting events, schools and universities, hotels and flights abroad to certain destinations (Twizer, 2021).

\subsection{Crisis Management}

Disasters expose existing failures and conflicts within organizations and in their connections to other organizations and support systems. The COVID-19 crisis is a global epidemic that has affected most of the world's population, has changed the world order, and created new life patterns in the fields of work from home, on-line commerce, on-line services, recreation, online formal and non-formal education, and more. These changes have created innovative areas of practice and require a re-examination of the new reality.

According to Mitroff (2004), different types of crises differ from each other typologically: Natural disaster or physical environment crises, Failure of technological systems crises, and human-created crises. Piotrowski (2006) examined the definition of crisis in the wake of Hurricane Katrina and its impact in New Orleans. In his work, it has been claimed that the intensity of the event was unpredictable, and therefore the response and the degree of control over it were limited.

Concerning Israel, (Eiland, 2020) noted that national crises like wars, terrorist attacks, and cyber-attacks, are specifically relevant to the state of Israel, in addition to crises like extreme climate and various epidemics. (Eiland, 2020) adds that the State of Israel has dealt with many national emergencies for security reasons over the years. As a result of this unique situation, Israel has accumulated unprecedented experience in rapid transitioning from routine to emergency. This experience is reflected in various capabilities and advanced organizational and technological systems (Eiland, 2020).

\subsection{The Readiness of Civil Society Organizations in Israel for the COVID-19 Pandemic}

The national crises that affected Israel throughout the years have always required, in addition to the actions of the central government, social and public 
mobilization for supportive actions and social initiatives. For this reason, social organizations of the third sector, which the community-centers are at their core, were called to the flag. Over the past few decades, many areas that were previously under the responsibility of government agencies of the first sector have been in the process of transferring to the responsibility of the third sector (Berman, 2002). The community centers are increasingly run by public-benefit corporations, associations, and local agencies that constitute the network of non-governmental, non-profit organizations. As a result of COVID-19, state budgets have been diminished, as well as state responsibility for community issues. However, the non-profit organizations of the third sector are intensifying and becoming major players in Israel, particularly in these times of crisis (Schmid, 2021).

This was the case, for example, during the Second Lebanon War (SLW), which lasted 34 days, from 12 July 2006 to 14 August 2006. According to the (Israel State Comptroller, 2007) on the deployment during the Second Lebanon War, the Israel Association of Community Centers (IACC) in the northern region-which is the main operator of community-centers in the north of Israel -focused on activities in four main areas: distributing food and equipment, organizing camps for children, caring for the elderly and those with special needs, and evacuating residents to refresh accommodation in the center and south regions of the country.

However, the COVID-19 Pandemic presented the community-centers with a different kind of challenge. According to (Schmid, 2021), the government of Israel, like many others in the world, was caught unprepared to deal with a pandemic of this magnitude. Furthermore, the COVID -19 pandemic caught Israel's Civil Society Organizations (CSOs) of the third sector in the middle of an ongoing financial crisis. Israel's CSOs needed new funding resources to finance the activities they wanted to run for the benefit of the community members. (Schmid, 2021) also describes the gap between the importance of the CSOs and the Israeli government's recognition of their needs and the assistance required for their functioning. It was claimed that Israeli third sector organizations understood that they were facing a particularly challenging period, in which, on one hand they would be forced to increase their activities, but on the other hand they will have to operate under strict and restrictive conditions (Schmid, 2021).

The third sector has suffered a severe blow as a result of the COVID-19 pandemic. The scope of work has increased, while donations have diminished in all organizations, from NPOs providing food, to NPOs that help the elderly or youth in need. The percentage of volunteers in CSOs also declined from $31.4 \%$ of the general population in 2019 to $8.1 \%$ in 2020, and contributions of households to CSOs have also decreased by 20\% compared to 2019 (Katz \& Feit, 2020). In order to survive and continue to provide the social services the CSOs used to provide for many years, they applied for financial aid from the government. However, their needs were not met by the government that has not put in place 
assistance plans for the CSOs. As a result, their activity almost shut down during the period of the COVID-19 pandemic. The business sector was the center of attention when it came to flowing financial aid, while the CSOs were left without answers. (Schmid, 2021) claims that the government ignored their needs because the CSOs wealth does not make money for the government. (Bode \& Brandsen, 2014) explained the tension between governments and NPOs in demands of governments for more accountability from NPOs, as a result of the expansion of partnerships between them.

Community-centers had to struggle in many fronts at the same time. They needed to protect the rights and salaries of their employees, to conduct alternative activities in accordance with the circumstances and limitations, to keep the maintenance of the buildings and facilities throughout the crisis, and to repeatedly prove their critical role in helping all those directly affected since the outbreak of the pandemic (the elderly, the unemployed, children, toddlers, etc.). Community-centers now needed to take immediate actions under circumstances of uncertainty. (Fowler et al., 2007) argued that managers' perception of readiness for crises in organizations is higher than that of the employees. Furthermore, it was claimed that organizations of the third sector are characterized in higher perception of readiness than organizations of the business sector. (Beck et al., 1992) argued that the success of an organization dealing with crises depends not only on its capability to respond, but on its ability to produce a changing response in the face of constant changes. The success of an organization to successfully deal with a crisis depends on its conduct, rather than on the characteristics of the crisis itself (Toffler \& Alvin, 1980). In fact, the need to deal with situations of uncertainty characterizes practically any activity in an organizational environment (Beck et al., 1992).

According to the (Israel State Comptroller, 2020), community-centers depend on the government and its sources of funding for their continued existence, as $41 \%$ of their budgets is based on government support. Despite all the difficulties, community-centers worked to bring community activity to the doorstep. Full accessibility was created, while maintaining the ministry of health regulations and protecting the health of customers and teams. Ideas and innovations that came up in one center, were very quickly spread between all the community-center, regardless of their affiliation with different operating frameworks. This may be due to the fact that all community-centers in Israel belong to the IFCC (the Israeli Federation of Community Centers) - an umbrella organization that unites the community centers and provides a platform for exchanging information and sharing practices.

Despite the deep economic crisis encountered by third sector organizations, the government was unable to set a criterion for distributing grants over many months, which has exacerbated the situation of the organizations even more. Over $50 \%$ of the organizations put employees on unpaid leave, and it is not at all clear whether they will ever return to their jobs. 25\% of the CSOs stopped work- 
ing altogether (Schmid, 2021). In the current crisis, NPOs' boards were unable to use their ties with government in order to gain the requisite support for the CSOs to continue to operate (Bibu \& Isler, 2019).

Despite the great complexity and many contradictions in the relationship between the third sector organizations with the authorities, community centers stood at the forefront during the COVID-19 pandemic crisis. Community centers led the emergency measures derived from the crisis, while they encountered existential difficulties, stemmed mainly from the problematic relationship with the central and local government (Almog-Bar, 2020). This situation highlighted the need to formulate patterns of collaborations between organizations of the third sector and between the government and the business sector, in order to be able to act jointly, especially in emergency situations (Schmid, 2021).

\subsection{Crisis Management-Models of Collaboration}

Many researchers have tried to develop tools for measuring the success of third sector organizations. These tools are inherently different from the tools that measure success in business organizations, where success is measured in terms of financial profit per capital, which the organization generates for its shareholders. Three models of collaboration, aimed at producing a common social impact, will be examined. All three models consider joint action, whether multi-sectoral or single sector, using the unique assets of each sector or organization (Shitufim, 2020). These models will serve as a theoretical framework for examining joint community action which is necessary to answer the research question at hand.

The Wisdom of the Crowd model (Model A) is based on the work of (Surowiecki, 2005). This model focuses on collective intelligence and combines perspectives from both social and business sectors. It attributes great power to the wisdom of the many, claiming that the many are smarter than the few and can therefore have a stronger influence and shape businesses, cultures and countries. According to this method, governments address the public, detailing the challenges involved in developing new capabilities, implementing advanced tools, changing existing laws, and more. These moves create transparency and public participation in government's activities contributing to community development.

In recent years, the use of inter-sectorial collaborations has expanded. The New Governance model (Model B) offers the participation of a larger public, social activism, public responsibility, and participatory democracy (Osborne, 2007). The "New Governance" model is for the organization of partners, such as governmental, social and economic bodies, that create collaborations between the public, business and civil society. This model describes a partnership that manages to bridge the gaps of organizational, cultural, and different institutional logic, differences of view, ideology, and values, while maintaining the unique identity of each of the partner organizations. The connections between the three bodies create a successful partnership that is also effective in achieving mutual goals (Schmid \& Almog-Bar, 2016). It is a partnership that creates new social, 
economic, technological, and other added values that generate a different kind of organizational dynamic and creates a synergy in which the whole is greater than the sum of its parts.

(Kania \& Kramer, 2011: p. 37) defined partnership in times of crisis as "an attempt by organizations to solve social problems in a collaborative way". Among the models which were examined, the recommended method was the Collective Initiatives Impact (Model C). This model emphasizes the attempt to lead a broad social impact as an ongoing framework of action for a common agenda of a group of key players from a variety of fields/sectors. Furthermore, this model highlights the importance of uniting all components on the way to an effective sphere of influence, starting from the work assumptions, required prerequisites and the core of the activity, in order to solve a social problem in a particular social field.

\subsection{The Research Question}

Despite the great difficulties described in the literature, community centers successfully continued operating throughout the COVID-19 crisis, leading the community and society in Israel. In this study, the reason for their success was examined, particularly the collaborations they have managed to spontaneously create during the crisis management. The purpose of this study was to examine each of the models and determine the one which results in the most desirable outcomes. The models which were successfully used by community centers were examined. Specifically, this paper intends to determine which model can be used for dealing with similar crises in the future.

\section{The Methodology}

The research was conducted in a qualitative approach. Interviews with leading figures were carried out alongside on-site observations in Community-centers in five local authorities of different regions, sectors, and socio-economic levels. This methodology was chosen based on the fact that throughout the entire period of the COVID-19 Pandemic outbreak, community-centers in all segments of the population, initiated situation-adapted activities. These activities involve original thinking, which was developed with great agility out of a desire to do good with the community, to maximize opportunities for closeness, help and encouragement. To best understand these dynamic operations, in-depth interviews were chosen as the tool best fit for the task.

\subsection{The Research Tools}

The research was based on qualitative information, which included open ethno-graphic in-depth interviews. Participants were asked about the dynamic relationships between their organizations and the municipality and other government bodies. Participants were asked to specify the activities their organizations initiated throughout the pandemic and the difficulties they encountered. Participants were assured that their anonymity would be maintained, and that the data 
would only be used for this study. As stated, the issues were examined in community-centers located in a representative sample of all local authorities in Israel. For the purpose of the study, they will be marked with the letters A-E. The findings are based on observations and interviews.

\subsection{The Research Population}

Five community-centers were included in the sample. Four centers (80\%) serve a Jewish community and one center (20\%) serves both Jewish and Arab communities. Three community-centers (60\%) serve religiously traditional communities, and two centers (40\%) serve secular communities. Three community-centers $(60 \%)$ are located in the center region of Israel, one center $(20 \%)$ is located in the east and one center (20\%) in the south. The (Israel Central Bureau of Statistics, 2021) characterizes and classifies geographical units by the level of Socio-Economic Status of the population (SES). The classification is based on ten different clusters, in which " 1 " is the lowest SES possible while "10" is the highest. The mean SES in this study was $7.6(\mathrm{SD}=1.14)$, which is considered high. One community-center was ranked $6(20 \%)$, one center was ranked $7(20 \%)$, two centers were ranked 8 (40\%) and the last was ranked 9 (20\%).

Ten senior managers were interviewed for the purpose of this study. Two managers are CEOs of community-centers, four managers the CEOs of the local association of community-centers in their authority, one the deputy CEO of the local association of community-centers, one the director of the community-centers department in the municipality, and one the regional head of the department in charge of program development. The mean age is 47.7 (SD =9.07). 7 men (70\%), and 3 women (30\%). The mean tenure in community managerial positions (experience) is 15.3 years $(\mathrm{SD}=9.08)$. All the managers have an academic diploma. 6 of them are bachelor's degree (60\%), and 4 are master's degree $(40 \%)$.

\section{Findings}

Unlike other crises, in which the different authorities often cooperate in their operations, the community-centers were caught unprepared and did not have the resources to initiate joint action. In emergency situations such as wars or natural disasters, community-centers focused on providing emergency treatment to whoever needed. In the conditions of the COVID-19 pandemic, this protocol does not apply. Therefore, the authorities focused on providing for their own community-centers, rather than cooperating for a broader approach.

\subsection{Local Authority A}

Local authority $\mathrm{A}$ is a large city in the center of the country, with a population of 450,000 . Socio-Economic rating is high. Number of community-centers in the city: 23. The network of community-centers is spread throughout the city and the work was carried out in a completely smooth manner, while coordinating 
local and state bodies. The city's many activities were marked "door closed, window opened". The city municipality decided that nothing is going to stop community activity. The organizing factor of the community activity, the municipality's community-centers division, continued to operate. The focus of responsibility and activity was transferred from the municipal hotline to the neighborhoods, most of which have operating community-centers.

Neighborhood managers were appointed. Sports and cultural activities were organized in the street and in public parks. Ideas from the field were adopted and immediately implemented. An online activity was conducted using the Zoom platform, including social gatherings, gymnastic classes, yoga, pilates and lectures in various areas of interest. WhatsApp groups have been set up to connect neighbors, so that quarantined people can keep up to date and maintain human contact with the outside world. Purchasing food for elderly who were not allowed to leave their homes was done in collaboration with other NPOs and volunteers from high schools and youth movements. Pairs of phone friends were established between teenagers from local high schools and youth movements, and senior citizens who were alone in their apartment. Internet connection and installation of computers including cameras, for distance learning and maintaining family ties, was carried out in collaboration with the authorities and other NPOs.

Another channel which was created during this period, was assisting local businesses in sales promotion and digital marketing throughout the pandemic. The interviewees noted that despite having received assistance and cooperation from all municipal divisions, their relationship with the governmental ministries was more distanced than before. The managers expressed a desire to keep community activity going, even in "field conditions".

\subsection{Local Authority B}

Local authority B is a medium sized city in the center of the country, with a population of 225,000. Socio-Economic rating is low. Number of community-centers: 11. Community-centers focused on events and recreational activities, in attempt to maintain personal and community morale. CEOs said that the centers tried to "keep their existence and not vanish". The public space was left physically empty, but digital spaces were created to complete the communal dimension. "The activity has gone out to the public spaces and the homes".

Music, acrobatics and other activities for families were organized all over the settlement. Meetings in the open air were organized between isolated seniors and their families. Performances of local artists were broadcasted live. As the population is religious, ceremonies of Shabbat candle lightings and prayers were held in each neighborhood. Traditional holiday dishes were distributed to the community. Sing-along meetings were held by local artists and sport activities for the elderly were held in the open air. The activity of the community-centers was under the guidance of the municipal company that encouraged cooperation with 
other sectors, such as municipal and state businesses and other organizations of the third sector.

The managers described that they believe the reason for the success of their activity was due to the fact that they did not have to deal with state authorities, who are perceived as bureaucratic and difficult to collaborate with. It was described that only with local elements they felt like they speak the same language. The managers reported that the means were sufficient to launch activities tailored to the circumstances and limitations. The managers were confident about the future. The underlying message was that when a local system is working properly during regular times, producing strong ties within the network, it will also work properly in crises.

\subsection{Local Authority C}

Local authority $\mathrm{C}$ is a medium sized city in the center of the country, with a population of 60,000 . Socio-Economic rating is high. Number of community-centers: 7. The community centers are run by a local NPO, which works in cooperation with the municipality and other authority bodies. The local NPO is responsible throughout the year on leisure culture. As leisure time has expanded during the times of the pandemic, the NPO leads and organizes all informal education and community activities. Informal education is flowing into the community-centers because they are the only available physical space that is functioning while schools are shut down. The community-center itself was busy enriching the growing leisure culture. Knitting groups, volunteering in hospitals, Zoom lectures, book lending services, online lessons for the entire family, joint holiday celebrations in open spaces, and more.

The managers reported that the municipality's economic stability freed the community-centers from the need to ask for help from external financing entities. Therefore, the economic burden was not the real problem, despite the temporary budget halt. The workers who left for an unpaid leave received assistance from the state, and those who remained in service operated the system sufficiently. One of the projects which was highlighted is called "residents for residents". This project included a special working model with a customized digital platform which was built especially. This platform allowed transverse connections to be formed between the residents who were working for themselves. The residents cooperated above and beyond what was expected, demand exceeded supply for participation in this project. The managers claimed that the strong municipal network, as well as the experience accumulated in handling emergency situations, both helped provide effective responses to the COVID-19 challenges.

\subsection{Local Authority D}

Local authority $\mathrm{D}$ is a medium sized city in the south of the country, with a population of 160,000. Socio-Economic rating is high. Number of community-centers: 
12. The community centers are run by a municipal company, so the activity was fully coordinated with the municipality and other local and governmental entities. The municipal company is in charge of many sectors in town. The company is labor-intensive and in times of routine provides great assistance to formal education by operating afternoon classes. This activity ceased during the closures and there was no longer a need to employ so many people who were placed in an unpaid leave. The focus shifted to working in cooperation with the welfare department for disadvantaged and at-risk populations. To this end, designated frameworks for preschoolers were activated. This activity was modified for digital enrichment, open-space activities and sports-all in accordance with the restrictions.

The managers reported that working through a municipal company, networked throughout the city and installed in all the educational platforms, produced a big advantage as a result of the shortcuts it allowed over the government bureaucracy. The managers also noted that financial difficulties still remained due to the decrease in revenues from the community-centers activities, which constituted a significant part of their budget. The community-centers also responded to the completely collapsed business sector, both in terms of population and business owners.

\subsection{Local Authority E}

Local authority $\mathrm{E}$ is a small and isolated urban settlement, with a population of 20,000. Socio-Economic rating is Low. Number of community-centers: 3. In routine times, the community center is the locomotive that leads society, culture, and community life in the city. The pandemic outbreak put much more saliency on the community-centers' activities. Since the community center in this town is the largest and almost exclusive establishment in charge of providing culture leisure and community services, the managers insisted on maintaining routine, even in this time of crisis. The collapse of the business sector had also left a void that was filled by the community centers.

The managers reported that the community-center received full cooperation from the local authority. The local authority fully backed the community-centers' operations and fully financed them as their "executive arm". The managers mentioned great difficulty in accessibility services, as a result of the great geographical distance new restrictions. The managers also noted that building a good network during routine times, was critical to function in such a crisis.

\section{Discussion of the Findings}

Five community-centers' networks from five different local authorities were surveyed through interviews and observations. Despite the difficulties in these times of pandemic, the managers showed original thought, goodwill to benefit the population and maximized possibilities for proximity, help and encouragement. The interviews and the observations in these five centers and municipali- 
ties clearly show that Crisis Model C-Collective Impact-was used to best suit the circumstances, allowing the community-centers to cope with the crisis by creating collaborations with other bodies.

Although the COVID-19 pandemic was a unique crisis that could not be expected, the training and experience of the managers helped greatly in coping with the new reality. The findings show that the community-centers are accustomed to adapting to new situations, even when the environment is changing rapidly and to unknown spheres. Thus, the community centers succeeded to solve acute problems during the pandemic, although the difficulties they faced were much greater than usual, due to fact that many employees in different ranks were on unpaid leave and problems needed ad-hoc solutions.

\section{Conclusion}

Third sector organizations possess organizational and social tools which are a considerable advantage in times of crisis and emergency. These tools include databases and knowledge that they acquire in daily contact with the population they serve, the smooth mechanisms of service and response to the community's needs, efficient organizational structure, and more. They have close relationships with the community members and community institutions as well as extensive experience in working directly with them. Furthermore, during a crisis, community centers can conduct themselves without unnecessary bureaucracy. However, the unexpected circumstances of the global pandemic, required an additional tool, and the research findings show that the chosen tool was collaborative work with other organizations-be it civil society organizations, government bodies, or other associations. In other words, the Collective Impact model was found to be the most effective in producing desired outcomes, with the community-centers at the core of the activity.

Put together, all these factors allowed the community centers to meet the challenges of the COVID-19 pandemic crisis. The community centers followed the course of action indicated in this model, meaning that organizations should solve social problems in a collaborative way. The community centers implemented the agenda that developed ad-hoc during the COVID-19 Pandemic and led collaborations by key players from a variety of sectors to solve social problems. This paper demonstrates the effective use of the Collective Impact model and how it yielded desired results throughout the COVID-19 pandemic. An important conclusion from this study is that third sector organizations might find increasing difficulty to operate without significantly expanding their ability to carry out collaborations. It is also recommended for future studies to continue this investigation as it has not been thoroughly researched yet.

\section{Conflicts of Interest}

The author declares no conflicts of interest regarding the publication of this paper. 


\section{References}

Almog-Bar, M. (2020). Volunteering and Social Involvement during the COVID-19 Crisis in Israel: Information, Insights, and Challenges. The Center for the Study of Civil Society and Philanthropy. The Hebrew University of Jerusalem and the Network of Israeli Volunteering. (In Hebrew)

Beck, U., Lash, S., \& Wynne, B. (1992). Risk Society: Towards a New Modernity (Vol. 17). Sage.

Berman, H. J. (2002). Doing “Good” vs. Doing "Well”: The Role of Nonprofits in Society. Blue Cross and Blue Shield Association, 39, 5-11. https://doi.org/10.5034/inquiryjirnl 39.1.5

Bibu, N., \& Isler, E. (2019). The Influence of Stakeholders on the Management and Work of a Community Center in Israel. In International Symposium in Management Innovation for Sustainable Management and Entrepreneurship (pp. 271-282). Springer. https://doi.org/10.1007/978-3-030-44711-3 20

Bode, I., \& Brandsen, T. (2014). State-Third Sector Partnerships: A Short Overview of Key Issues in the Debate. Public Management Review, 16, 1055-1066.

https://doi.org/10.1080/14719037.2014.957344

Cohen, M. (2021). Coronavirus Supervisor: As of Today, Coronavirus Vaccines Will Not Be Required in Isolation. Walla News 17.1.2021. (In Hebrew)

https://news.walla.co.il/item/3412086

Eiland, G. (2020). Managing the Coronavirus Crisis in Israel. In Hashiloah, Israeli Journal of Contemplation and Policy. (In Hebrew)

Elkayam, O., Stein, A., \& Dor, K. (2020). CEO of the Israel Ministry of Health: "First Confirmed Case of Coronavirus in Israel”. Kan.

https://www.kan.org.il/Item/?itemId=67303

Fowler, K. L., Kling, N. D., \& Larson, M. D. (2007). Organizational Preparedness for Coping with a Major Crisis or Disaster. Business \& Society, 46, 88-103.

https://doi.org/10.1177/0007650306293390

Israel Central Bureau of Statistics (2021). Socio-Economic Index of Local Authorities. https://www.cbs.gov.il/en/subjects/Pages/Socio-Economic-Index-of-Local-Authorities. aspx

Israel Ministry of Health (2020a). Accessible Information about the Coronavirus. https://www.gov.il/he/departments/guides/accessible-info-corona

Israel Ministry of Health (2020b). Quarantine Information. https://www.gov.il/he/departments/guides/corona-quarantine

Israel Ministry of Health (2021). Coronavirus in Israel-Situation Update. https://datadashboard.health.gov.il/COVID-19/general

Israel State Comptroller (2007) Report on Home Front deployment and functioning in the Second Lebanon Wa.

Israel State Comptroller (2020). Report on the Local Authorities 2020. https://www.mevaker.gov.il/sites/DigitalLibrary/Documents/2020/Shilton-2020/2020-S hilton2020-104-Matnasim.pdf?AspxAutoDetectCookieSupport=1

Kania, J., \& Kramer, M. (2011). Collective Impact (pp. 36-41). FSG.

Katz, H., \& Feit, G. (2020). Individual Giving and Volunteering in Israel during the COVID-19 Crisis: The Second Wave, Part 2. The Institute for Law and Philanthropy, The Buchmann Faculty of Law, Tel Aviv University.

Marziano, M. (2021). Edelstein: More than $50 \%$ of Israeli Citizens Were Vaccinated in the Second Dose. (In Hebrew) 
https://13news.co.il/item/news/domestic/health/corona-in-israel-1228327

Mitroff, I. I. (2004). Think like a Sociopath, Act like a Saint. Journal of Business Strategy, 25, 42-53. https://doi.org/10.1108/02756660410558933

Osborne, S. P. (2007). The New Public Governance? Public Management Review, 8, 377-388. https://doi.org/10.1080/14719030600853022

Piotrowski, C. (2006). Hurricane Katrina and Organization Development: Part 1. Implications of Chaos Theory. Organization Development Journal, 24, 10.

Schmid, H. (2021). Reflections on the Relationship between the Government and Civil Society Organizations during the Covid-19 Pandemic: The Israeli Case. Nonprofit Policy Forum, 12, 189-197. https://doi.org/10.1515/npf-2021-0003

Schmid, H., \& Almog-Bar, M. (2016). Inter-Sectoral Collaborations in Israel: Process Inputs and Outputs-Research Findings and Implications for Policy and Practice. Center for the Study of Civil Society and Philanthropy in Israel. (In Hebrew)

http://.sw.huji.ac.il/list/945

Shitufim (2020). Three Models of Joint Action-Three Models of Action Aimed at Producing a Common Social Impact. (In Hebrew)

https://app.activetrail.com/S/xiwiefeetzw.htm

Surowiecki, J. (2005). The Wisdom of the Crowds: Why the Many Are Smarter than the Few and How Collective Wisdom Shapes Business, Economics, Societies, and Nations. Anchor.

Toffler, A., \& Alvin, T. (1980). The Third Wave (Vol. 484). Bantam Books.

Twizer, I. (2021). For the First Time in Israel: O Coronavirus Infections. N12, 23.4.2021. (In Hebrew)

https://www.mako.co.il/news-lifestyle/2021 q2/Article-58e2ace349df871027.htm

WHO World Health Organization (2020). Disease Outbreak News. https://www.who.int/emergencies/disease-outbreak-news 